\title{
USING COMSOL MULTIPHYSICS IN STUDY OF BEEBREAD DRYING MODES
}

\author{
Sergei Oskin, Sergey Kharchenko, Dmitry Tsokur \\ Kuban State Agrarian University named after I.T. Trubilin, Russia \\ kgauem@yandex.ru, ser.harchenko1995@yandex.ru,dmitry_tsokur@mail.ru
}

\begin{abstract}
One of the most important bee products for humans is beebread, as it has dietary and healing properties. After gathering, beebread has a high humidity - about $30 \%$ and it must be dried to $18 \%$ state that it can be stored. It is usually dried in convective drying installations. However, most dryers have a common disadvantage - there is a large spread in the drying time between the trays filled with beebread. The purpose of these studies was to intensify the drying process in the first period due to the short-term supply of additional thermal energy. The arrival of increased heat in the first period will allow the source material to heat up faster to the set temperature and start the evaporation process from the surface earlier. The main task was without changing the design of the dryer to recommend a new mode of operation, which would reduce the spread of humidity parameters between the trays. A geometric model of the object of research has been developed for its introduction into the Comsol software product. A mathematical model of the main physical processes occurring in the drying chamber is obtained, which makes it possible to analyze the main parameters that affect the drying rate. The modeling was carried out in two stages. At the first stage, the normal operation mode was investigated with three variants of the supplied thermal power of $300 \mathrm{~W}, 340 \mathrm{~W}$, and $400 \mathrm{~W}$. At the second stage, a new regime was investigated. It consists in a temporary summing up of the thermal power equal to $500 \mathrm{~W}$ for 2 hours and returning to the previous power in all three variants. As a result of the analysis of the obtained data, it was found that the drying time in all modes is from 22 to 30 hours. However, the humidity spread between the upper and lower trays reaches up to $13 \%$ with a constant power supply mode, whereas with a temporary power supply only up to $7 \%$ of humidity. In addition, in the normal mode, the difference in drying time between the extreme trays was from $26 \mathrm{~h}$ to $20 \mathrm{~h}$, when applying increased power, the difference is $7 \mathrm{~h}$. Thus, there is a more uniform drying process for all the trays.
\end{abstract}

Keywords: drying, beebread, modeling, convection, moisture.

\section{Introduction}

The process of drying the initial product is a necessary procedure for most technologies of processing agricultural products. It is known that this process is quite energy-intensive and lengthy. There are certain drying modes for each feedstock, which allows to get output products with good quality. Most of the raw materials to be processed are dried for 10 to 18 hours. Of course, the drying time is highly dependent on the initial moisture content of the product and the process can be extended for a longer time [1].

Mass-produced dryers often use the convective method of drying - the transfer of heat to the dried product by heated air [2]. Installations of this type have specific energy consumption at the level of 1.6$2.5 \mathrm{kWh} \cdot \mathrm{kg}^{-1}$. This is a significant amount of energy, but the simplicity of the design of these dryers gives them a significant advantage in the sales market over other types of dryers that use other drying methods.

The role of bees in the agro-industrial complex is great as producers of specific products - honey, wax, pollen, royal jelly, propolis and bee venom. The most well-known food is honey, but there are other equally popular products, such as beebread. It is known that the main useful property of beebread is the tonic effect on the human body. When used, it increases muscle strength, immunity, stimulates mental activity, improves appetite, and improves mood. In this regard, beebread is used not only as a medical remedy, but also as a dietary product rich in protein substances, carbohydrates, vitamins and trace elements $[3 ; 4]$.

After gathering the pollen grain, it contains about $20-30 \%$ of moisture. The presence of such a large amount of moisture in the pollen grain creates favorable conditions for the development of different types of microorganisms, especially micromycetes, so this raw material is dried (dehydrated) to a humidity of 8-10\% [5]. There are also requirements of TU 10 RF 505-92 "Dried beebread", in which the product humidity is allowed no more than $18 \%$. It is established that at a residual humidity of no more than $10 \%$, the beebread has well been preserved for several years. A necessary condition for drying is the heating temperature of the pollen grain, which should not exceed $37-40{ }^{\circ} \mathrm{C}$, otherwise individual hormones, enzymes, and vitamins are destroyed $[2 ; 6 ; 7]$. 
Usually there are lattice trays in the drying chamber, on which an even layer of $1.0-1.5 \mathrm{~cm}$ of pollen grain is sprinkled. The fan blows heated air between the trays. The duration of drying at a moisture content of $20-25 \%$ usually lasts about 24 hours, and at a humidity of 30-35\% - up to 72 hours. Currently, there are many offers on the market for equipment for drying raw materials, including beebread. For the most part, these installations are designed according to the mine type. The heat carrier enters the chamber, where several trays with the product are located. Passing through the trays, the dry air is saturated with moisture and is removed outside [2].

During traditional convective drying, the heat carrier is used once and therefore the energy consumption of the technological process is high and amounts to $34.4 \mathrm{kWh} \cdot \mathrm{kg}^{-1}$ of the resulting product [8].

To reduce the energy consumption of the drying process, there are proposals for repeated use of the coolant. The replacement of the heat carrier with fresh atmospheric air occurs periodically with an increase in its humidity to $75-80 \%$. On this basis, special designs of drying installations were developed $[9 ; 10]$.

Researchers from the Ryazan State Agrotechnological University named after P. A. Kostychev have developed the installation for beebread drying with a significant reduction in energy consumption [9]. The reduction in energy consumption is achieved by repeatedly passing the same air through the drying chamber. After the air is filled with critical moisture, it is removed, and new air enters the drier and the process is repeated. Despite the reduction in energy consumption, the drying time increased by $25 \%$, which is sometimes unacceptable.

The purpose of these studies was to try to reduce the beebread drying time in the first place and to equalize the final moisture content of the product in all the trays as much as possible.

\section{Materials and methods}

The change in the average moisture content of the material over time is called the drying kinetics, and it depends on the properties of a particular product. A typical view of the drying kinetics is shown in Figure 1. As a rule, there are two specific sections of the drying curve: the period of constant drying speed (section $\mathrm{AB}$ ) and the period of variable or falling drying speed (section $\mathrm{BC}$ ).

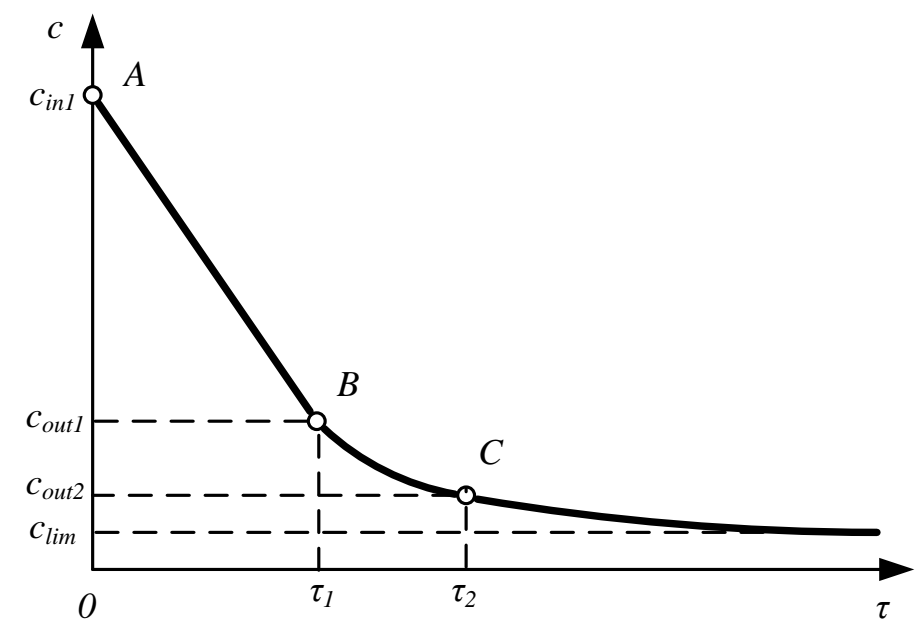

Fig. 1. Kinetics of the initial material drying

The first section is characterized by the fact that there is a process of surface evaporation. In this case, the surface of the material is covered with moisture and there is a compensation of evaporating moisture due to its diffusion from the inner layers. The rate of moisture diffusion is equal to the rate of water evaporation from the product surface. The process speed is limited by the surface evaporation rate.

The amount of vaporized liquid in the first drying period can be determined by the formulas [11]:

$$
W=F \beta_{x}\left(x_{1}-x\right) ; W=F \beta_{p}\left(p_{1}-p\right)
$$


where $F$ - surface area of the phase contact;

$x_{1}, x$-moisture content of saturated air in the drying conditions and the actual humidity, respectively;

$p_{1}, p$ - partial pressure of saturated air and actual partial pressure of air, respectively;

$\beta_{x}, \beta_{p},-$ mass transfer coefficients;

$\tau_{1}$ - duration of drying.

It is established that the main factors determining the drying rate in the first period are: humidity of the coolant, its temperature and the speed of movement, evaporation surface. It should be noted that the temperature of the coolant affects the drying rate through the elasticity of the saturated steam.

It was decided to intensify the drying process in the first period due to the short-term supply of additional heat energy. The arrival of increased heat in the first period will allow the source material to heat up faster to the set temperature and start the evaporation process from the surface earlier.

To implement mathematical models of moisture transport, the Comsol Multiphysics package was used. The geometric model of the object of the research is shown in Figure 2. The dryer has an inlet air heater, trays with beebread, and a fan for supplying the coolant to the drying chamber. The heater and fan are installed outside the chamber. The main task was not to change the design and try to speed up the drying process on the original equipment by changing only the operating mode. Reducing the drying time will increase the productivity of the installation, which is very important when receiving a large amount of gathered beebread. In such cases, it is necessary to process quickly the raw material and prevent it from becoming covered with mold.

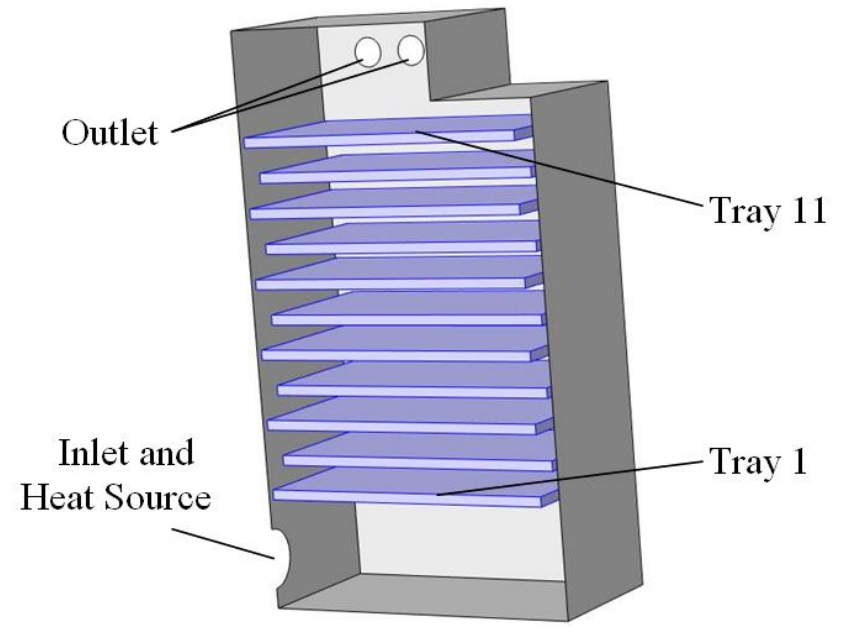

Fig. 2. Geometrical model of the object of research

The equation of the fluid flow associated with the air exchange can be described on the basis of the Navier-Stokes equations (continuity of medium and equation of motion) [12]:

$$
\left\{\begin{array}{l}
\frac{\partial \rho}{\partial t}+\nabla \cdot(\rho u)=0 \\
\rho \frac{\partial u}{\partial t}+\rho u \cdot \nabla u=-\nabla p+\nabla \cdot\left(\mu\left(\nabla u+(\nabla u)^{T}-\frac{2}{3} \mu(\nabla \cdot u) I\right)\right)+F
\end{array},\right.
$$

where $\rho, u$-air density and velocity;

$p$-pressure;

$\mu$ - coefficient of dynamic viscosity;

$I$ - unit vector;

$F$ - additional force pressure.

The main equation of the heat current movement can be described by the equation:

$$
\rho \cdot c_{p} \cdot \frac{\partial T}{\partial t}+\rho \cdot c_{p} \cdot u \cdot \nabla T+\nabla q=\sum Q_{h} .
$$


where $c_{p}$ - heat capacity of medium;

$u$ - current velocity;

$q=-\lambda \nabla T-$ heat current density;

$\Sigma Q_{h}-$ general intensity of heat emissions.

Modeling of changes in the humidity regime was carried out with the analysis of the processes of diffusion and convection, described taking into account the laws of Fick and Darcy. The beebread was represented by a porous structure with corresponding permeability coefficients. In general, the equation of moisture transport has the form:

$$
\frac{\partial c_{i}}{\partial t}+\nabla \cdot\left(-D_{i} \nabla c_{i}\right)+u \cdot \nabla c_{i}=0,
$$

where $c_{i}$ - concentration of $i$-substance;

$D$ - coefficient of diffusion of $i$-substance (in the model the diffusion coefficient is taken as a constant).

In the model the beebread is represented as a porous structure (porosity is assumed to be 0.5 ). Heat insulation condition was applied to the walls of the chamber. Air velocity at the inlet of the drying chamber was equal to $1.5 \mathrm{~m} \cdot \mathrm{s}^{-1}$. The temperature of air entering the drying chamber was equal to $20^{\circ} \mathrm{C}$, and its relative humidity was equal to 0.3 . The same value of initial moisture content was accepted for beebread. The density, heat capacity and thermal conductivity of beebread were assumed to be $1250 \mathrm{~kg} \cdot \mathrm{m}^{-3}, 2000 \mathrm{~J} \cdot \mathrm{kg}^{-1} \cdot \mathrm{K}^{-1}$ ) and $0.2 \mathrm{~W} \cdot \mathrm{m}^{-1} \cdot \mathrm{K}^{-1}$ ), respectively. The thickness of the layer of beebread poured in each tray was $2 \mathrm{~cm}$. The length and width of the tray are $0.6 \mathrm{~m}$ and $0.63 \mathrm{~m}$, respectively. The drying chamber has dimensions of $1.15 \times 0.65 \times 0.65 \mathrm{~m}$. In the model, the outdoor air inlet section is also the source of heat (Fig. 2).

All the individual physical processes were connected via the Comsol multiphysical interface. Modeling was performed for two variants. At the first variant, drying was carried out with a constant heat output of $300 \mathrm{~W}, 340 \mathrm{~W}, 400 \mathrm{~W}$. The main limitation of the input power was the temperature of the material - it should not be higher than $45^{\circ} \mathrm{C}$ [2; 7]. At the second variant, the heat output of $500 \mathrm{~W}$ was temporarily supplied for 2 hours, after which it was returned to the previous installed capacity. There were 11 trays in the dryer. The study time was 30 hours.

\section{Results and discussion}

The solution of mathematical models in the form of temperature graphs is presented in Figures 3, 4, 5. Figures 3a, 4a, 5a refer to the certificate drying mode, and Figures $3 b, 4 b, 5 b$ refer to the new one with variable heat output.
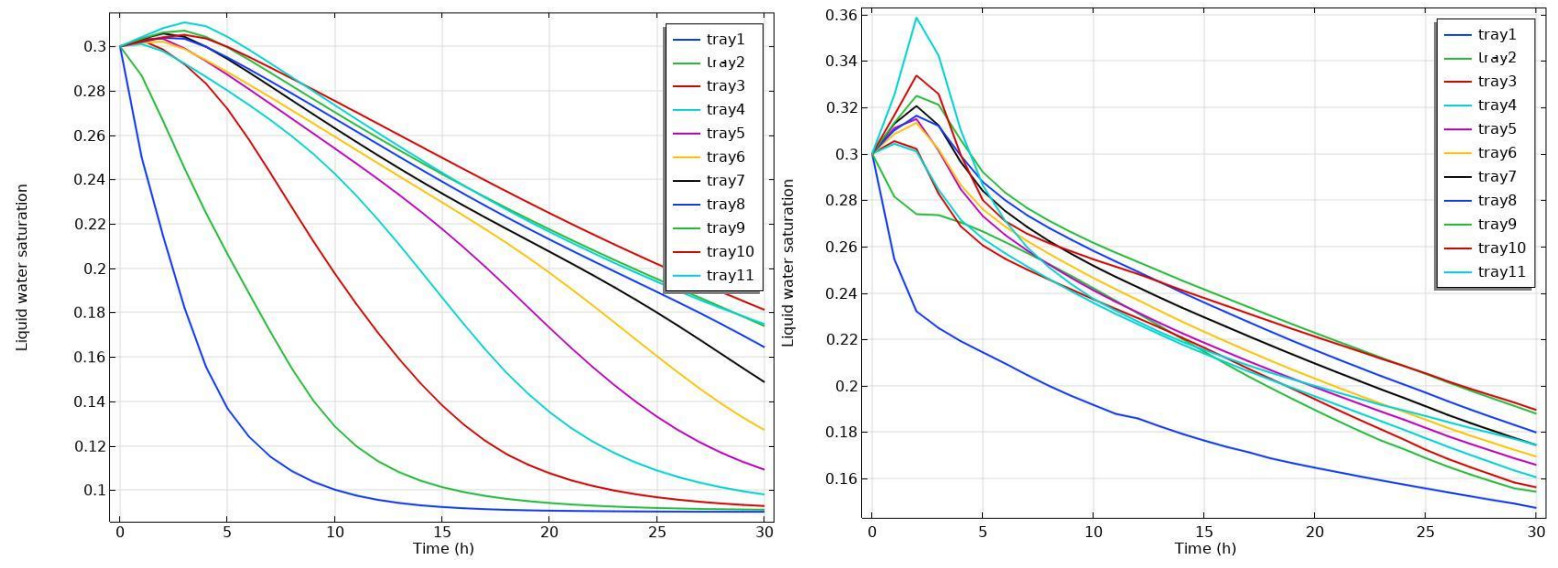

Fig. 3. Graphs of dependence of the change in humidity of beebread placed in separate trays when the thermal power of $300 \mathrm{~W}$ is supplied in a constant mode (a), temporary supply of increased heat (b) 

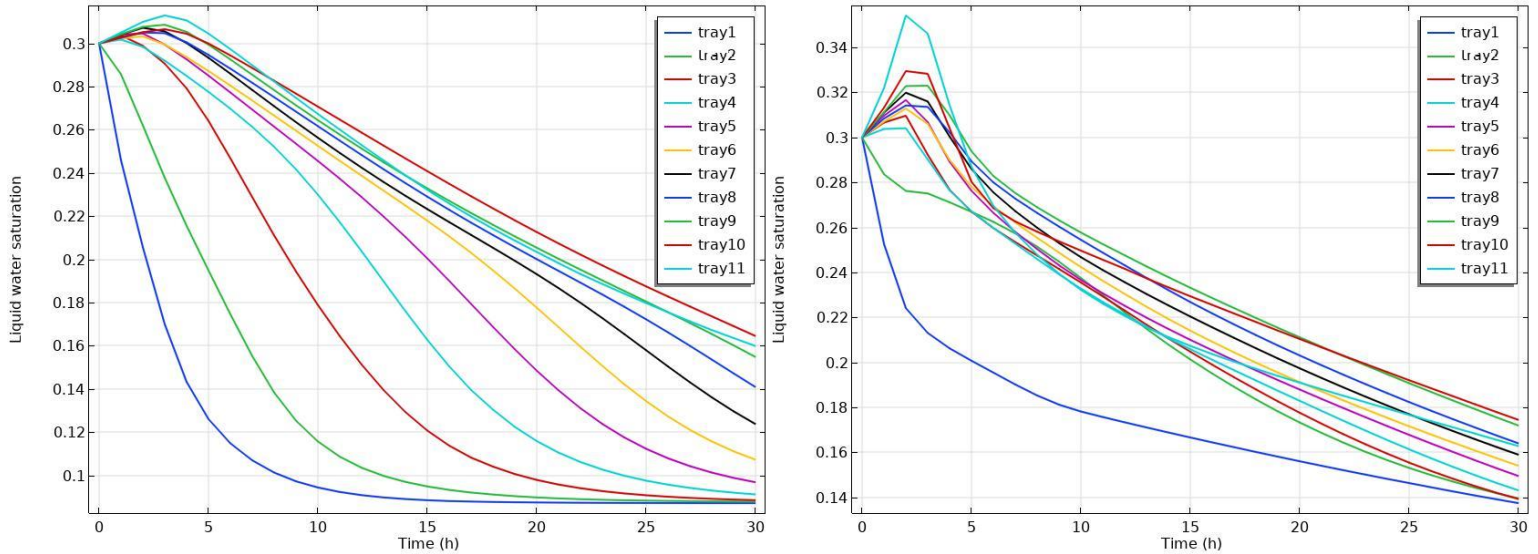

Fig. 4. Graphs of dependence of the change in humidity of beebread placed in separate trays when the thermal output of $340 \mathrm{~W}$ is supplied in a constant mode (a), temporary supply of increased heat $(b)$
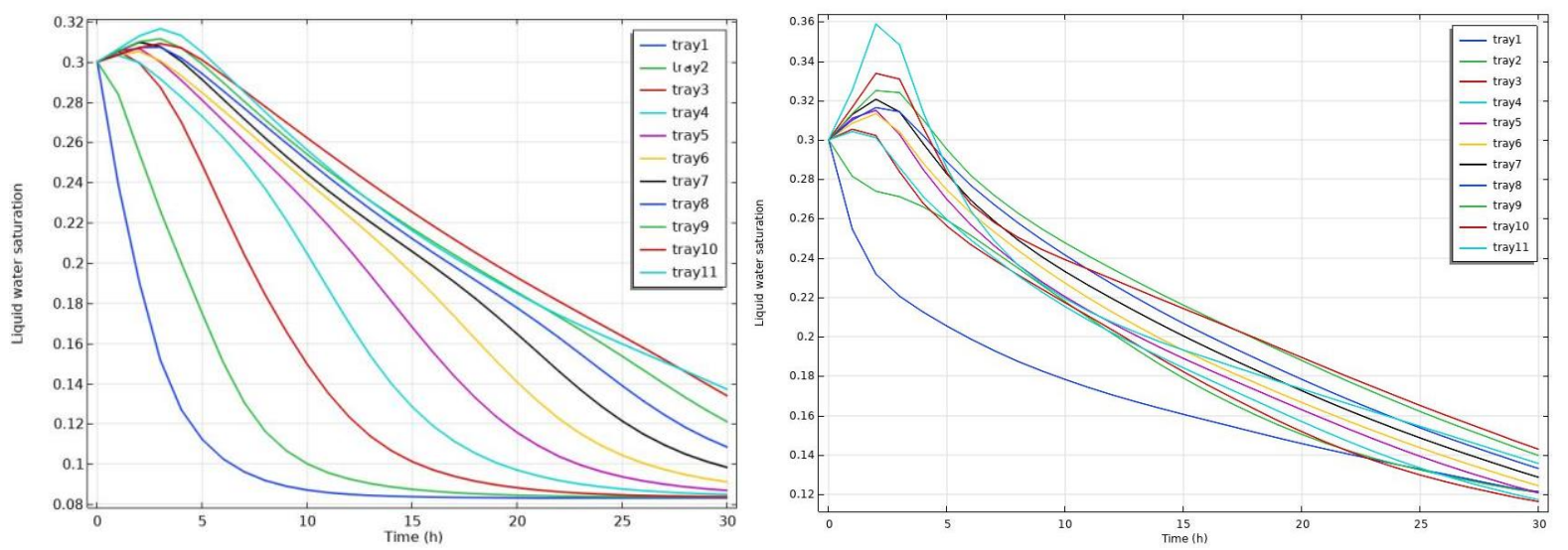

Fig. 5. Graphs of dependence of moisture content of beebread placed in separate trays with thermal power $400 \mathrm{~W}$ in continuous regime (a), temporary supply of high heat (b)

In these figures it is possible to observe not simultaneous drying of the material in all the trays, but this is especially noticeable in Figures 3a, 4a, 5a. With constantly supplied power, the beebread dries very quickly in the lower trays, for example, in the first three - up to 15 hours (Fig. 3a, 4a, 5a). At the same time, in the upper trays, after 30 hours, only at a power of $400 \mathrm{~W}$, the beebread reaches a conditioned humidity of $14 \%$. Figures $3 \mathrm{~b}, 4 \mathrm{~b}, 5 \mathrm{~b}$ are characterized by a more uniform moisture content of the material on all trays. If you look at the difference in the humidity of the material between the trays after 30 hours, you can see that when the power is $300 \mathrm{~W}$, it is $13 \%$ (Fig. 3a), at $340 \mathrm{~W}-11 \%$ (Fig. 4a), at $400 \mathrm{~W}-6 \%$ (Fig 5a). If a temporary increased heat flow is created, then at a constant thermal power of $300 \mathrm{~W}$, the difference becomes 11\% (Fig. 3b), at $340 \mathrm{~W}-3 \%$ (Fig. 4b), at $400 \mathrm{~W}-2 \%$ (Fig. 5b). The analysis of Fig. 3a, 4a, 5a also shows that the lower trays with beebread can dry out very much, and this also worsens the quality of the products. There is a large difference in the drying time between the trays - it is in the range from 20 to 26 hours. When applying temporarily increased heat, the time difference is only 7 hours (Fig. $3 b, 4 b, 5 b$ ).

The increase in power during the first 2 hours of drying to $500 \mathrm{~W}$ leads to an increase in total energy consumption of $4.4 \%$ (in the case of $300 \mathrm{~W}$ in the following 28 hours), $3.1 \%$ (in the case of $340 \mathrm{~W}$ ) and $1.7 \%$ (in the case of $400 \mathrm{~W}$ ). As it can be seen from Figures 3, 4, 5, such a slight increase in total energy consumption significantly affects the uniformity of drying of the product in the trays. This allows the product quality to be maintained.

Studies carried out on the basis of a drying chamber operating in the standard mode (which corresponds to Fig. 3a, 4a, 5a) showed the adequacy of the theoretical results obtained. 


\section{Conclusions}

Drying of beebread is a long process taking up to 30 hours. There is also a big difference in the final humidity in individual trays with the product. There is a need to reduce the total drying time and to equalize the final humidity in all trays only by changing the modes of the drying equipment. It is suggested in the initial period of work to supply an increased value of heat power, so that the source material is heated faster and the process of moisture evaporation from its surface begins earlier.

A geometrical model of the research object was developed to be introduced in the Comsol software product. The corresponding mathematical models of the main physical processes occurring in the drying chamber were selected in the program, which make it possible to analyze the equipment parameters affecting the speed of drying.

The solution of mathematical models in Comsol with the use of multiphysics coupling of thermal, moisture and hydrodynamic processes in the drying chamber was carried out. The analysis of the drying kinetics graphs showed the following: the supply of increased power in the initial period allows increasing the uniformity of drying of all trays and reducing the difference in the moisture content between the trays by 2 times. The new mode eliminates the possibility of over-drying of the lower trays.

\section{References}

[1] Aboltins A., Upitis A. Experimental and theoretical investigation of agricultural material drying process. Proceedings 11th International Scientific Conference "Engineering for Rural Development", Jelgava: LLU, 2012. pp. 93-98.

[2] Midilli A., Olgun H., Ayhan T. Experimental studies on mushroom and pollen drying. International Journal of Energy Research 23(13), 1999. pp. 1143-1152.

[3] Urcan A., Marghitas L.A., Daniel Severus Dezmirean, etc. Chemical Composition and Biological Activities of Beebread. Bulletin of University of Agricultural Sciences and Veterinary Medicine Cluj-Napoca Animal Science and Biotechnologies 74(1), 2017, 6 p.

[4] Shavrina D.I., Nesterova N.V., Nesterova O.V. etc. Studying Possibilities of Using Beebread in Medicine with the Follow-Up Development of a Means to Improve Immunity. RUDN Journal of Medicine 23(4), 2019. pp. 412-417.

[5] State Standard 28887-2019. Flower beebread. Technical conditions. Moscow, Standartinform Publ., 2019. 27 p. (In Russian)

[6] Aboltins A., Palabinskis J., Vartukapteinis K. Studies of berry drying process in infrared film dryer. Proceedings 16th International Scientific Conference "Engineering for Rural Development", Jelgava: LLU, 2017. pp. 1515-1520.

[7] Barajas J., Rodríguez M.C., Rodriguez-Sandoval E. Effect of temperature on the drying process of bee pollen from two zones of Colombia. Journal of Food Process Engineering 35(1), 2012. pp. 134-148.

[8] Nekrashevich V.F., Bronnikov V.I., Vinokurov S.V. Methods of beebread drying. Proceedings of scientific works, vol. 2, 2000, pp. 58-59.

[9] Каширин Д.Е. Установка для сушки перги в сотах (Installation for beebread drying). Patent RF, No 2275563, 2006 (In Russian).

[10] Каширин Д.Е. Установка для сушки перги в сотах (Installation for beebread drying). Patent RF, No 2391610, 2010, (In Russian).

[11]Горбунцова С.В., Муллоярова Э.А., Оробейко Е.С. Физическая и коллоидная химия (в общественном питании) (Physical and colloidal chemistry (in catering)), 2016. 270 p. (In Russian).

[12] CFD Module User's Guide. COMSOL. 